\title{
Para Lá do Fenómeno Cultural: A Mutilação Genital Feminina como um Problema de Saúde Pública em Portugal
}

\author{
Beyond the Cultural Phenomena: Female Genital \\ Mutilation as a Public Health Problem in Portugal
}

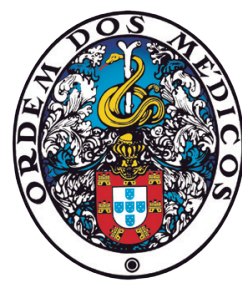

Margarida PAIXÃO', João VALENTE², Andreia LEITE $\bigotimes^{3,4,5}$, em Representação da Equipa de Implementação do Projeto "Práticas Saudáveis - Fim à Mutilação Genital Feminina"

Equipa de implementação do projeto "Práticas Saudáveis - Fim à Mutilação Genital Feminina":

António Carlos da SILVA, Diana CHAVES, Lucinda SILVA, Mário DURVAL, Nuno LOPES, Vânia TEIXEIRA, Vítor PEDRO Acta Med Port 2021 Jun;34(6):410-412 - https://doi.org/10.20344/amp.15536

Palavras-chave: Circuncisão Feminina/economia; Circuncisão Feminina/efeitos adversos; Portugal

Keywords: Circumcision, Female/adverse effects; Circumcision, Female/economics; Portugal

A mutilação genital feminina (MGF) é definida pela Organização Mundial da Saúde (OMS) como "a prática que envolve a remoção (parcial ou total) ou lesão dos órgãos genitais femininos externos por motivos não médicos". A realização da mesma prende-se com crenças tradicionais, não religiosas, sendo considerada um pré-requisito para o casamento e para garantir a virgindade feminina. ${ }^{1}$ Segundo a OMS, a MGF é classificada em quatro tipos principais (Tabela 1). O presente artigo visa caracterizar este problema de saúde em Portugal e detalhar iniciativas realizadas para a prevenção do mesmo, nomeadamente no âmbito da formação dos profissionais de saúde.

De acordo com estimativas do Fundo das Nações Unidas para a Infância (UNICEF), aproximadamente $200 \mathrm{mi}-$ Ihões de meninas/mulheres foram submetidas à prática a nível mundial. A prevalência da MGF é maior em países do continente Africano e Médio Oriente, mas também em certos grupos da América Central e América do Sul. ${ }^{2}$

Em Portugal, a prevalência da prática está associada ao perfil de imigração do país, verificando-se essencialmente em imigrantes oriundos de países da África subsariana. ${ }^{3}$ Segundo o estudo de prevalência realizado em 2015 pelo Centro de Estudos de Sociologia da Universidade Nova de Lisboa, cerca de 5246 mulheres em idade fértil residentes em Portugal foram submetidas à prática, na maioria provenientes da Guiné-Bissau (91\%), mas também de outros países como a Guiné-Conacri (3\%) e o Senegal (2\%). A grande maioria destas mulheres residia no distrito de Lisboa $(70 \%){ }^{3}$

Adicionalmente, da análise dos dados do Registo de Saúde Eletrónico entre abril de 2014 e dezembro de 2017, identificaram-se 237 registos de casos de mutilação, maioritariamente do tipo I (41\%) e II (55\%). Todos foram registados por profissionais de unidades pertencentes à Região de Saúde de Lisboa e Vale do Tejo. Segundo o documento, a prática da MGF ocorreu fora do país em todos as situações sinalizadas, maioritariamente na Guiné-Bissau (58\%). Em $74 \%$ das situações foi possível apurar a idade em que a prática foi realizada, tendo-se verificado que, em média, ocorreu aproximadamente aos sete anos. ${ }^{4}$

A prática de MGF constitui uma violação dos direitos humanos, nomeadamente do direito à vida, à integridade física e à saúde, e do direito à igualdade e não discriminação. Viola, igualmente, os direitos da criança, dado a prática ser, na sua grande maioria, praticada em menores de idade. Consequentemente, é ilegal em Portugal, de acordo com o artigo $144^{\circ}$-A do Código Penal Português. ${ }^{5} \mathrm{~A}$ legislação determina que, para além da prática, constituem atos ilegais todos os atos preparatórios para a mesma, nomeadamente a programação da viagem, quer para o país onde a mesma vá ocorrer, quer para trazer a Portugal quem a vá realizar. ${ }^{3}$

A MGF tem impacto na saúde a curto e a longo prazo, ${ }^{1}$ sendo que as complicações a curto prazo se prendem, essencialmente, com as condições em que é efetuada. ${ }^{6,7}$ Destas, destaca-se a hemorragia como complicação mais frequente, geralmente por laceração das artérias pudenda interna ou clitoriana. ${ }^{6} \mathrm{~A}$ infeção é outra complicação frequente, podendo culminar em choque séptico. Existe alguma literatura a apontar para um maior risco de infeção pelo vírus da imunodeficiência humana e hepatites $\mathrm{B}$ e $\mathrm{C}$ associado ao instrumento usado para o corte. ${ }^{6,7}$ Contudo, a evidência é limitada e não existem estimativas da incidência deste tipo de infeções.

\footnotetext{
1. Unidade de Saúde Pública António Luz. Agrupamento de Centros de Saúde da Amadora. Amadora. Portugal.

2. Departamento de Saúde Pública. Administração Regional de Saúde de Lisboa e Vale do Tejo. Lisboa. Portugal.

3. Escola Nacional de Saúde Pública. Universidade NOVA de Lisboa. Lisboa. Portugal.

4. Public Health Research Centre. NOVA National School of Public Health. Universidade NOVA de Lisboa. Lisboa. Portugal.

5. Comprehensive Health Research Center (CHRC). Lisboa. Portugal.

$\triangle$ Autor correspondente: Andreia Leite. andreia.leite@ensp.unl.pt

Recebido: 16 de dezembro de 2021 - Aceite: 23 de fevereiro de 2021 - First published: 19 de março de 2021 - Online issue published: 01 de junho de 2021

Copyright (๑) Ordem dos Médicos 2021
} 
Tabela 1 - Classificação da mutilação genital feminina em quatro tipos, de acordo com a Organização Mundial da Saúde

\begin{tabular}{ll}
\hline Tipos & Descrição \\
\hline Tipo I & Remoção parcial ou total do clítoris e/ou do prepúcio (clitoridectomia) \\
& Tipo la - Remoção do prepúcio do clítoris; \\
& Tipo lb - Remoção do clítoris com o prepúcio. \\
Tipo II & Remoção parcial ou total do clítoris e dos pequenos lábios, com ou sem excisão dos grandes lábios \\
& Tipo lla - Remoção apenas dos pequenos lábios; \\
& Tipo llb - Remoção parcial ou total do clítoris e dos pequenos lábios; \\
& Tipo llc - Remoção parcial ou total do clítoris, dos pequenos lábios e dos grandes lábios. \\
Tipo III & Estreitamento do orifício vaginal através da criação de uma membrana selante, através de corte e aposição dos pequenos \\
& lábios e/ou dos grandes lábios, com ou sem excisão do clítoris (infibulação) \\
& Tipo Illa - Remoção e aposição dos pequenos lábios; \\
& Tipo Illb - Remoção e aposição dos grandes lábios. \\
Tipo IV $\quad$ Atos não classificados: todas as outras intervençães nefastas sobre os orgãos genitais femininos por razões não \\
médicas, por exemplo: punção/picar, perfuração, incisão, corte, escarificação e cauterização
\end{tabular}

Fonte: Organização Mundial da Saúde, $2020^{1}$

A longo prazo, a MGF pode causar fístulas génito-urinárias, dor pélvica crónica, ausência de prazer sexual, dispareunia, disfunção sexual (devido à formação de tecido cicatricial) e infertilidade (associada a dispareunia e à disfunção sexual previamente mencionadas). Adicionalmente, associa-se a uma maior probabilidade de partos distócicos, com complicações associadas (como por exemplo, lacerações perineais e hemorragia pós-parto), assim como a um aumento da morbimortalidade perinatal. ${ }^{6}$

A MGF também tem impacto na saúde mental (como por exemplo, ansiedade, depressão e síndrome de stress pós-traumático) quer direta, quer indiretamente, devido às complicações previamente mencionadas. ${ }^{8}$

As opções terapêuticas perante um caso de MGF podem ser divididas em quatro categorias: i) tratamento de suporte em caso de hemorragia e/ou infeção imediatamente após a prática; ii) 'de-infibulação' (i.e. encerramento parcial do orifício vaginal) em situações de MGF tipo III e em algumas de tipo II, em particular durante a gravidez; iii) tratamento cirúrgico para outras complicações a longo-prazo (como por exemplo, fístulas); e iv) acompanhamento no âmbito da saúde mental. ${ }^{6}$

O impacto económico da prática encontra-se pouco estudado. Estima-se que o Serviço Nacional de Saúde inglês gaste entre $€ 44$ a $€ 215$ milhões anualmente em tratamentos por complicações da MGF. ${ }^{8}$ Segundo a OMS, em seis países africanos com elevada prevalência de MGF (Burkina Faso, Gana, Nigéria, Quénia, Senegal e Sudão), o tratamento de complicações obstétricas decorrentes da mutilação poderá representar $0,1 \%$ a $1 \%$ do orçamento para a saúde das mulheres entre os 15 - 45 anos. Para além do tratamento das complicações obstétricas, estima-se que 130000 anos de vida sejam perdidos, situação cujo impacto económico não foi calculado. ${ }^{9}$

A literatura referente à avaliação de intervenções para a prevenção da prática de MGF é também limitada. Contudo, alguma evidência sugere que a adequada formação dos profissionais que se possam deparar com casos de MGF leva a maior identificação de situações de risco/perigo e de ocorrência de MGF e, consequentemente, a atuação atempada. A criação de equipas multidisciplinares para avaliação e discussão das opções terapêuticas e sociais de todos os casos de mulheres sinalizadas no bloco de partos também se revelou uma solução efetiva. ${ }^{10}$

Em Portugal, iniciou-se em novembro de 2018 o projeto "Práticas Saudáveis: Fim à Mutilação Genital Feminina", que resulta de uma parceria entre o Alto Comissariado para as Migrações, a Comissão para a Cidadania e a Igualdade de Género e a Administração Regional de Saúde de Lisboa e Vale do Tejo. O projeto, com a duração inicialmente prevista de dois anos, foi em fevereiro de 2020 prorrogado até final de 2021. Assim, o projeto que inicialmente se limitava aos territórios das unidades de Saúde Pública (USP) de Almada-Seixal, Amadora, Arco Ribeirinho, Loures-Odivelas e Sintra, abrange atualmente também os territórios das USP de Cascais, Estuário do Tejo, Lisboa Central, Lisboa Ocidental e Oeiras e Lisboa Norte. ${ }^{11}$

As três áreas de ação previstas são: i) integração da MGF em instrumentos de política pública, aumentando o seu reconhecimento; ii) capacitação e formação de profissionais e iii) intervenção comunitária.

Desde fevereiro de 2018 que profissionais das três organizações parceiras do projeto, em articulação com elementos-chave da comunidade, têm desenvolvido diversas ações. Ao nível do eixo i) destacam-se a elaboração de planos de ação e a integração em vários instrumentos de trabalho nos territórios-alvo do projeto da temática. ${ }^{12}$ Ao nível do eixo ii) durante o ano de 2019, tiveram lugar 68 formações que abrangeram 1176 profissionais dos agrupamentos de centros de saúde, docentes e não docentes de estabelecimentos de educação e ensino, técnicos de autarquias e de organizações não governamentais e alunos do ensino superior. As formações tiveram como objetivo informar sobre a prática, os recursos disponíveis e qual a meIhor atuação, de acordo com as orientações. É de salientar a formação de profissionais de saúde em pós-graduação 
específica sobre MGF que teve lugar em 2019, estando prevista para 2021 nova edição, na qual serão formados os novos líderes do projeto a nível local. Ao nível do eixo iii) destacam-se o desenvolvimento de materiais para divulgação e colaboração com organizações não governamentais nos territórios de atuação. ${ }^{11,12}$

Está prevista a continuidade das atividades do projeto nos seus diversos eixos, nomeadamente na formação de profissionais dos Agrupamentos de Centros de Saúde participantes. Pretende-se desta forma salientar a importância da formação dos profissionais, levando a uma maior identificação das situações de risco/perigo e de ocorrência de MGF, e permitindo uma atuação atempada . As avaliações

\section{REFERÊNCIAS}

1. Organização Mundial da Saúde. Female genital mutilation. 2020. [consultado $2021 \mathrm{fev}$ 17]. Disponível em: https://www.who.int/newsroom/fact-sheets/detail/female-genital-mutilation.

2. Fundo das Nações Unidas para a Infância. Female genital mutilation/ cutting: a statistical overview and exploration of the dynamics of chance. New York: UNICEF; 2013.

3. Lisboa M, Cerejo D, Teixeira A, Santana R, Luís AA, Teixeira AB, et al. Mutilação genital feminina: prevalências, dinâmicas socioculturais e recomendações para a sua eliminação- Relatório final. Lisboa: Faculdade de Ciências Sociais e Humanas, Universidade NOVA de Lisboa; 2015.

4. Serviços Partilhados do Ministério da Saúde, Direção-Geral da Saúde. Mutilação genital feminina - análise de casos registados na PDS/RSEPP 2014-2017. Lisboa: DGS; 2018.

5. Portugal. Decreto-Lei n. ${ }^{\circ} 48 / 1995$. Diário da República, Série IA, n. ${ }^{\circ} 63$ (1995/03/15).

6. World Health Organization. WHO Guidelines on the Management of Health Complications from Female Genital Mutilation. Geneve: WHO; 2016.

7. lavazzo C, Sardi TA, Gkegkes ID. Female genital mutilation and infections: a systematic review of the clinical evidence. Arch Gynecol Obstet. 2013;287:1137-49. de impacto das intervenções locais desenvolvidas no âmbito do projeto irão permitir verificar o sucesso das ações de prevenção. ${ }^{11}$

\section{FONTES DE FINANCIAMENTO}

Os autores não receberam financiamento para a redação do presente artigo.

\section{CONFLITOS DE INTERESSE}

Os autores Margarida Paixão e João Valente integram a equipa local e regional do projeto "Práticas saudáveis - fim à mutilação genital feminina".

8. Hex N, Hanlon J, Wright D, Dale V, Bloor K. Estimating the costs of female genital mutilation services to the NHS. York: University of York; 2016. [consultado 2021 fev 17]. Disponível em: https://allcatsrgrey. org.uk/wp/download/governance/clinical_governance/safeguarding/ EstimatingCostsOfFGMServices.pdf.

9. Bishai D, Bonnenfant YT, Darwish M, Adam T, Bathija H, Johansen E et al. Estimating the obstetric costs of female genital mutilation in six African countries. Bull World Health Organ. 2010;88:281-8.

10. Njue C, Karumbi J, Esho T, Varol N, Dawson A. Preventing female genital mutilation in high income countries: a systematic review of the evidence. Reprod Health. 2019;16:113.

11. Comissão para a Cidadania e Igualdade de Género. Apresentados os resultados do projeto "Práticas Saudáveis: Fim à Mutilação Genital Feminina." [consultado 2020 set 13]. Disponível em: https://www. cig.gov.pt/2020/02/apresentados-os-resultados-do-projeto-praticassaudaveis-fim-mutilacao-genital-feminina/.

12. Comissão para a Cidadania e Igualdade de Género. Portugal Mais Igual - Estratégia Para a Igualdade e Não Discriminação 2018-2030 - Relatório Intercalar de Monitorização 2019. Lisboa: CIG; 2020. [consultado 2021 fev 17]. Disponível em: https://www.cig.gov.pt/wpcontent/uploads/2018/07/Relatório-Intercalar-de-Monitorização-2019. pdf. 